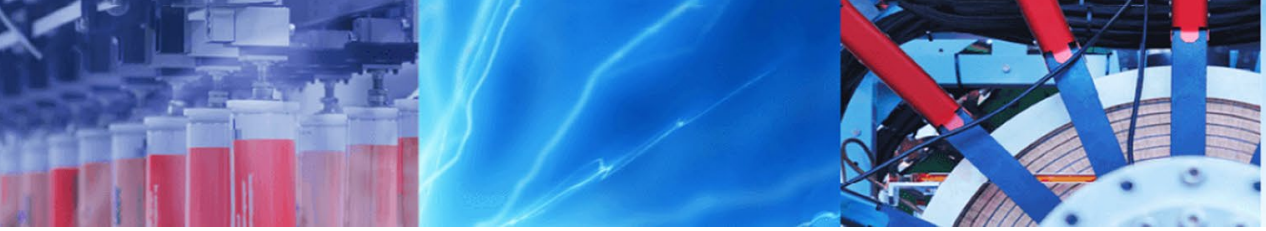

Research Article

\title{
Influence of medium on structure, morphology and electrochemical properties of polydiphenylamine/vanadium pentoxide composite
}

\author{
Halima Khatoon ${ }^{1} \cdot$ Sajid Iqbal $^{1}$. Sharif Ahmad' ${ }^{1}$ (1)
}

(c) Springer Nature Switzerland AG 2019

\begin{abstract}
A facile, one-pot oxidative polymerization approach was used to synthesize polydiphenylamine (PDPA) and polydiphenylamine/vanadium pentoxide (PDPA $/ \mathrm{V}_{2} \mathrm{O}_{5}$ ) composite using APS as an oxidizing agent. The reactions were carried out in two different reaction media (i.e. aqueous and acidic). The influence of these two mediums on molecular structure, morphology and thermal stability was investigated using FTIR spectroscopy, X-ray diffraction, SEM-EDS and thermogravimetric analysis. The temperature dependent electrical conductivity and dielectric properties (dielectric loss and dielectric constant) of these materials were also conducted. These studies revealed that in aqueous medium PDPA/ $\mathrm{V}_{2} \mathrm{O}_{5}$ composite has formed however, in acidic medium only the PDPA polymer formed, suggesting different nature of $\mathrm{V}_{2} \mathrm{O}_{5}$ in these two medium. The results also showed that the PDPA $/ \mathrm{V}_{2} \mathrm{O}_{5}$ composite has higher yield, good electrical conductivity, charge transport, dielectric losses and thermal properties as compared to that of PDPA. Furthermore, the electrochemical properties were evaluated by cyclic voltammetry, and electrochemical impedance spectroscopy and found that PDPA/ $\mathrm{V}_{2} \mathrm{O}_{5}$ composite shows good electrochemical properties.
\end{abstract}

Keywords Polydiphenylamine $\cdot$ Vanadium pentoxide $\cdot$ Reaction medium $\cdot$ Electrochemical properties

\section{Introduction}

Continuous efforts for the development of strategic materials with controlled structure and property relationship have suggested a new direction for the formulation of polymer-metal oxide composites, with versatile properties. These polymer-metal oxide composites have wide applications in the field of energy storage, solar cell, batteries and supercapacitors [1-3]. These materials came to the new track, especially after the discovery of conducting polymers (CPs). CPs possess unique optical property, high electrical conductivity, good thermal and environmental stabilities, and inherent microporosity [4]. CP have versatile applications in the field of supercapacitors, batteries, solar cells, corrosion guards etc. [5-7]. However, it has been observed that CPs alone have failed to provide high conductivity and value added properties. Thus, to overcome these drawbacks researchers have moved towards the synthesis of their copolymers and composites by incorporating metal oxide into the $\mathrm{CP}$ matrix. Various metal oxides such as nickel oxide, cobalt oxide, manganese oxide, copper oxide vanadium oxide etc., have intensively been used due to their availability, chemically stability, mechanically, eco-friendly, and high performances in supercapacitor application $[8,9]$. On this account, the introduction of transition metal oxide in CPs has gained more attention, which shows good expandability, chemical resistance and cation exchange ability [10,11]. Among these, the introduction of $\mathrm{V}_{2} \mathrm{O}_{5}$ in $\mathrm{CPs}$ has attained a great deal of attention due to their various promising properties including their interesting charge transport characteristics, that make them suitable for various applications $[12,13]$. The interaction between $\mathrm{CP}$ and $\mathrm{V}_{2} \mathrm{O}_{5}$ influences the polymer conformation, chain length, and electron transport properties [12].

Sharif Ahmad, sharifahmad_jmi@yahoo.co.in; Halima Khatoon, hkn.nasir02@gmail.com; Sajid Iqbal, saj143frnd@gmail.com | 1Jamia Millia Islamia, New Delhi 110025, India.

SN Applied Sciences (2019) 1:261 | https://doi.org/10.1007/s42452-019-0285-y 
Moreover, the synergistic effects of $\mathrm{V}_{2} \mathrm{O}_{5}$ and CPs generate the electron transport between the $\mathrm{CP}$ and $\mathrm{V}_{2} \mathrm{O}_{5}$, which ultimately led to the development of new properties.

Literature reveals that several groups have reported the composite of $\mathrm{V}_{2} \mathrm{O}_{5}$ with different $\mathrm{CPs}$ like polypyrrole, polyaniline, polythiophene and their derivatives. However, the Polyaniline (PANI) and its derivatives (alkyl or aryl substituted) have extensively been studied because of their good solubility and ease of synthesis [14]. Amongst these, Polydiphenylamine (PDPA), an N-substituted derivative of PANI, consisting intermediate properties of polyaniline and poly (phenylene) have emerged as a new conducting polymer [15]. Several reports have been published for the chemical and electrochemical synthesis of PDPA and PDPA composite $[16,17]$. It has been noted that the synthesis and morphology of CPs and CP based composites are strongly affected by the selection of different catalysts and the reaction media used [18]. For instance, Tao et al. [19] have reported the synthesis of aniline oligomers in alkaline solution, which was further used as a seed to grow the PANI nanofibers in acidic solution. Further, they have reported that the synthesis is low cost environment friendly. Further, in a study reported by Katarzyna et al. [20], the effect of reaction medium ( $m$-cresol, DMSO, and NMP) on conductivity and morphology of PANI doped with camphorsulphonic acid. They have inferred that the composite synthesized in presence of $\mathrm{m}$-cresol, exhibited good conductivity and uniform and continuous polymer films. While the composite with DMSO and NMP, showed non-uniform and granular films with lower conductivity. To the best of our knowledge, no work has been reported till date on the influence of reaction medium (aqueous and acidic) in the processing of PDPA and PDPA $/ \mathrm{V}_{2} \mathrm{O}_{5}$ composite. Interestingly $\mathrm{V}_{2} \mathrm{O}_{5}$, in these reaction mediums is able to alter the bulk properties of PDPA and PDPA $/ \mathrm{V}_{2} \mathrm{O}_{5}$ composite.

On this account, here we report one pot facile synthesis of polydiphenylamine $/ \mathrm{V}_{2} \mathrm{O}_{5}$ composite in two different media i.e. aqueous $\left(\mathrm{H}_{2} \mathrm{O}\right)$ and acidic $(\mathrm{HCl})$. The influence of these media on their structural, morphological, thermal and electrical behaviour was investigated. It was found that in aqueous medium PDPA $/ \mathrm{V}_{2} \mathrm{O}_{5}$ composite has formed, which exhibited better thermal and electrical properties than PDPA polymer that synthesized in acidic medium.

\section{Experiment}

\subsection{Materials}

Diphenylamine (DPA) monomer $\left(\mathrm{C}_{12} \mathrm{H}_{11} \mathrm{~N}\right.$, mol. wt. 169.22) Merck Germany, Vanadium pentoxide $\left(\mathrm{V}_{2} \mathrm{O}_{5}\right.$, mol. wt.
181.88) Thomas baker chemicals, Ammonium peroxydisulphate (APS, mol. wt. 228) Alfa Aesar, hydrochloric acid $(\mathrm{HCl}$, mol. wt. 36.46, \%assay 36.5, sp. gravity 1.18 ) Merck India and distilled water.

\subsection{Synthesis}

PDPA $/ \mathrm{V}_{2} \mathrm{O}_{5}$ was synthesized according to our previously reported work [21]. However, to investigate the effect of medium, the same was synthesized in acidic medium. In the process, $0.507 \mathrm{~g}(0.01 \mathrm{~mol})$ fine powder of vanadium pentoxide $\left(\mathrm{V}_{2} \mathrm{O}_{5}\right)$ was dissolved in $50 \mathrm{~mL}$ of $1 \mathrm{M} \mathrm{HCl}$ and taken in a round bottom flask fitted with thermometer, ice bath and magnetic stirrer. Further, the addition of $1.69 \mathrm{~g}(0.01 \mathrm{~mol})$ of DPA monomer was carried out that provides pre-oxidative polymerization of DPA, which was established by the change in colour from yellow to light green. After this, $50 \mathrm{~mL}$ of $0.01 \mathrm{~m}$ APS aqueous solution was added dropwise that further changes the colour from light to dark green indicating that APS promotes the oxidising ability of $\mathrm{V}_{2} \mathrm{O}_{5}$ in $\mathrm{HCl}$ medium. The reaction was further proceed for $24 \mathrm{~h}$. After the completion of reaction, precipitate of was filtered, washed and dried at $80^{\circ} \mathrm{C}$ for $24 \mathrm{~h}$ in oven.

This indicates that the presence of $\mathrm{V}_{2} \mathrm{O}_{5}$ alone does not contribute to the polymerization of DPA, as no change in colour was observed. This behaviour suggest that the $\mathrm{V}_{2} \mathrm{O}_{5}$ does not participate in the oxidation of DPA monomer for its polymerization. However, $\mathrm{V}_{2} \mathrm{O}_{5}$ gets enveloped by PDPA and formed PDPA $/ \mathrm{V}_{2} \mathrm{O}_{5}$ composite. The reaction was further allowed to proceed for $24 \mathrm{~h}$. After the completion of reaction, the precipitate of PDPA/ $\mathrm{V}_{2} \mathrm{O}_{5}$ composite was filtered, washed with distilled water and methanol repeatedly until the filtrate become colourless. The collected composite was dried at room temperature $\left(37^{\circ} \mathrm{C}\right)$ followed by further drying at $80^{\circ} \mathrm{C}$ for $24 \mathrm{~h}$ in oven.

\subsection{Materials characterization}

The structural characterization of the PDPA polymer and PDPA $/ \mathrm{V}_{2} \mathrm{O}_{5}$ composite was carried out with the help of Fourier Transform Infrared (FTIR) spectra (Shimadzu FT-IR spectrometer) using $\mathrm{KBr}$ pellets. The advance $\mathrm{X}$-ray diffractometer (Rigaku Rodaflex 200B) was used to record the $X$-ray diffraction (XRD) patterns at the $2 \theta$ range of $10^{\circ}-70^{\circ}$ using $\mathrm{Cu}$ Ka radiation. The morphology and elemental analysis were characterized by SEM and EDS analysis using EVO18, Carl Zeiss, Germany equipped with EDS detector. The electrical properties of PDPA $/ \mathrm{V}_{2} \mathrm{O}_{5}$ composite and PDPA were characterized by temperature dependent DC conductivity meter in the temperature range 364-463 K. For measuring the DC conductivity, the pellets of the synthesized composites were used. A constant voltage of $1.5 \mathrm{~V}$ 
was applied across the pellets and measured the current. The temperature was measured with the help of copperconstantan thermo couple, which was kept between the two steel electrodes.

The electrochemical property of polymer and polymer composite was studied by cyclic voltammetry, measured by Autolab type III potentiostat ( $\mu 3$ AVT70762 Netherland). The measurement was carried out in $0.5 \mathrm{M} \mathrm{H}_{2} \mathrm{SO}_{4}$ aqueous solution on a standard three-electrode system using platinum wire as a counter electrode and $\mathrm{Ag} / \mathrm{AgCl}$ (saturated $\mathrm{KCl}$ ) as the reference electrode, respectively. The $\mathrm{CV}$ curves were recorded in the potential window from +1.2 to $-1.2 \mathrm{~V}$ (vs. Ag/AgCl) at scan rate of $2 \mathrm{mV} / \mathrm{s}$. Electrochemical cyclic stability of the electrodes were also carried out by CV over 200 cycles. The electrochemical impedance measurements were carried out in a frequency range of $10 \mathrm{~Hz}-100 \mathrm{MHz}$ using Wayne Kerr 6500B instrument.

\section{Results and discussion}

$\mathrm{V}_{2} \mathrm{O}_{5}$ behaves differently in aqueous and acidic medium. In aqueous medium, the conversion of DPA into PDPA $/ \mathrm{V}_{2} \mathrm{O}_{5}$ composite was initiated after the addition of APS, which can be said by observing the change in colour from yellow to green. This indicates that the presence of $\mathrm{V}_{2} \mathrm{O}_{5}$ alone does not contribute to the polymerization of DPA as no change in colour was observed. This behaviour also suggest that the $\mathrm{V}_{2} \mathrm{O}_{5}$ does not participate in the oxidation of DPA monomer for its polymerization. However, $\mathrm{V}_{2} \mathrm{O}_{5}$ gets enveloped by the PDPA and forms PDPA $/ \mathrm{V}_{2} \mathrm{O}_{5}$ composite. While in acidic medium the pre-oxidative polymerization of DPA monomer occurs without adding APS, which was established by the change in colour from yellow to light green. The colour of the reaction further changed upon the addition of $1 \mathrm{M} \mathrm{HCl} /$ APS solution. Additionally, it was observed by the following characterization techniques that the composites obtained in aqueous reaction medium showed good thermal and electrical properties than the polymer obtained in acidic medium. Schematic representation for the formation of composite and polymer have given in Fig. 1.

\subsection{FTIR}

The FTIR absorbance spectra of PDPA $/ \mathrm{V}_{2} \mathrm{O}_{5}$ composite and PDPA are given in Fig. 2a, b respectively. The broad and intense absorption band at $3388 \mathrm{~cm}^{-1}$ and $3381 \mathrm{~cm}^{-1}$ in PDPA $/ \mathrm{V}_{2} \mathrm{O}_{5}$ composite and PDPA corresponds to $-\mathrm{NH}$ - stretching. The absorbance band at $1590 \mathrm{~cm}^{-1}$, $1491 \mathrm{~cm}^{-1}$, and $1316 \mathrm{~cm}^{-1}$ are due to $\mathrm{C}-\mathrm{H}$ stretching in the quinoid, phenyl and benzenoid rings, respectively [22]. A slight shifting of these peaks (i.e. from 1484 and $1310 \mathrm{~cm}^{-1}$ for phenyl hydrogen and benzenoid ring respectively) have occurred in PDPA synthesized in $\mathrm{HCl}$ medium as compared to that of PDPA $/ \mathrm{V}_{2} \mathrm{O}_{5}$. The peaks at 1170 and $1163 \mathrm{~cm}^{-1}$ in PDPA $/ \mathrm{V}_{2} \mathrm{O}_{5}$ and PDPA, respectively, corresponds to the vibration of $\mathrm{N}$-atom attached to the quinoid ring [14]. The absorption band at $815 \mathrm{~cm}^{-1}$ and $806 \mathrm{~cm}^{-1}$ in PDPA and PDPA $/ \mathrm{V}_{2} \mathrm{O}_{5}$ corresponds to vibration (a)

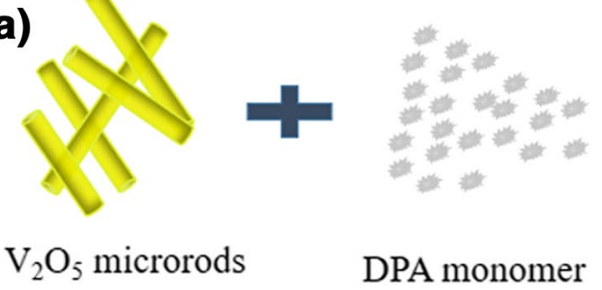

(b)

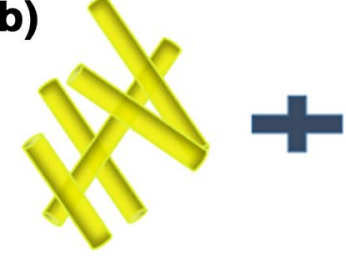

$\mathrm{V}_{2} \mathrm{O}_{5}$ microrods

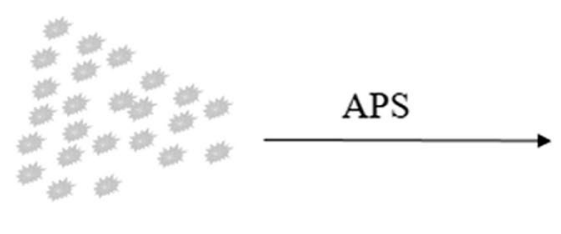

DPA monomer
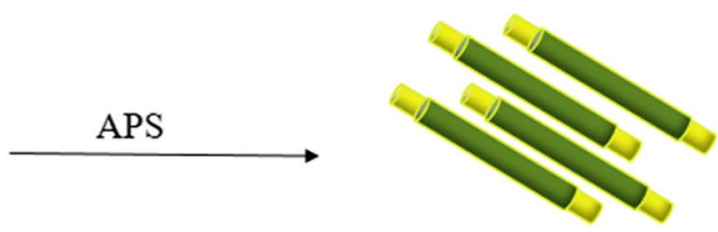

DPA monomer polymerizes on the surface of $\mathrm{V}_{2} \mathrm{O}_{5}$

Fig. 1 Mechanism of formation of PDPA/ $\mathrm{V}_{2} \mathrm{O}_{5}$ composite in $\mathbf{a}$ aqueous and PDPA in $\mathbf{b}$ acidic mediums 


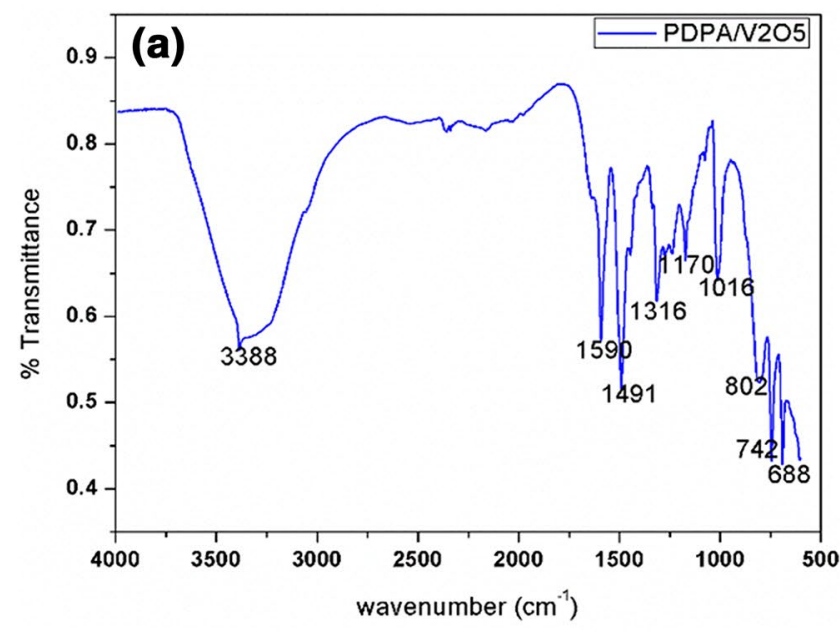

Fig. 2 FTIR spectra of a PDPA $/ \mathrm{V}_{2} \mathrm{O}_{5}$ b PDPA

of the 1,4-disubstitude aromatic ring. The peak at $742 \mathrm{~cm}^{-1}$ in PDPA $/ \mathrm{V}_{2} \mathrm{O}_{5}$ and $749 \mathrm{~cm}^{-1}$ in PDPA corresponds to the $\mathrm{C}-\mathrm{H}$ out of plane [23]. An addition peak with high intensity appeared at $1016 \mathrm{~cm}^{-1}$ can be attributed to the $\sigma-\pi$ interaction between $\mathrm{V}_{2} \mathrm{O}_{5}$ [24]. Moreover, the hydrogen bonding between PDPA and oxygen atoms on the surface of $\mathrm{V}_{2} \mathrm{O}_{5}$ in the composites further confirms the enwrapping of $\mathrm{V}_{2} \mathrm{O}_{5}$ by PDPA.

\subsection{SEM-EDS}

SEM images of $\mathrm{V}_{2} \mathrm{O}_{5}$, PDPA $/ \mathrm{V}_{2} \mathrm{O}_{5}$ composite and PDPA are depicted in Fig. 3a-c. Figure 3 a clearly confirmed the rod like structure of $\mathrm{V}_{2} \mathrm{O}_{5}$, while PDPA and PDPA $/ \mathrm{V}_{2} \mathrm{O}_{5}$ composite exhibited irregular granules (Fig. $3 \mathrm{C}$ ) and rod (Fig. $3 \mathrm{~b}$ ) like morphology, respectively. The $\mathrm{V}_{2} \mathrm{O}_{5}$ particles exhibit random one-dimensional growth in aqueous environment. The porous behaviour of this rod like growth is also visible in case of PDPA $/ \mathrm{V}_{2} \mathrm{O}_{5}$ composites that develop more homogeneous one-dimensional rod like particle in layered manner. On the other hand, the PDPA processed in acidic medium in presence of $\mathrm{V}_{2} \mathrm{O}_{5}$ particles failed to enwrap the inorganic phase of $\mathrm{V}_{2} \mathrm{O}_{5}$, which may be due to its complete leaching during the polymerization of DPA resulting in the formation of fully porous structure of PDPA. The morphology changed from rod to fully porous granular structure with the change in reaction medium from aqueous to acidic can be explained by the fact that $\mathrm{V}_{2} \mathrm{O}_{5}$ is soluble in acidic medium that make the DPA monomer more hydrophilic, while the insolubility of $\mathrm{V}_{2} \mathrm{O}_{5}$ in pure aqueous $\left(\mathrm{H}_{2} \mathrm{O}\right)$ medium provides hydrophobic nature to DPA [25, 26]. Hence, the hydrophilic nature of DPA monomer in $1 \mathrm{M}$ $\mathrm{HCl}$ medium reduces the repulsion between the charged hydrophilic groups that destroyed the morphology of $\mathrm{V}_{2} \mathrm{O}_{5}$ resulting in irregular granules of PDPA [18]. On the other

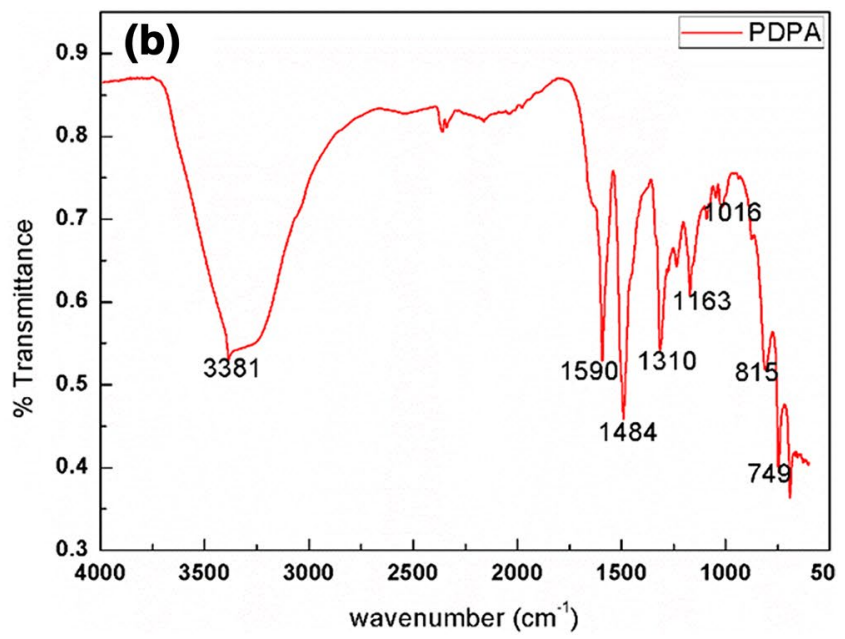

hand, the hydrophobic DPA monomer in pure aqueous medium possess higher surface tension that led the processing of $\mathrm{V}_{2} \mathrm{O}_{5}$ rod template, which can be responsible for the formation of rods like structure of PDPA $\mathrm{N}_{2} \mathrm{O}_{5} \mathrm{com}$ posite. The energy dispersive $\mathrm{X}$-ray spectra of PDPA/ $/ \mathrm{V}_{2} \mathrm{O}_{5}$ (Fig. 3d) and PDPA (Fig. 3e) further confirms the presence of vanadium element in aqueous medium, while in acidic medium it is absent.

\subsection{XRD}

XRD measurements were conducted to determine the structure of the $\mathrm{V}_{2} \mathrm{O}_{5}$, PDPA and PDPA $/ \mathrm{V}_{2} \mathrm{O}_{5}$ and have shown in Fig. $4 \mathrm{a}-\mathrm{c}$. The orthorhombic phase of $\mathrm{V}_{2} \mathrm{O}_{5}$ has shown highly crystalline nature. The XRD pattern of PDPA (Fig. 4c) shows a diffraction pattern exhibiting the characteristics peaks of PDPA at $18^{\circ}$ and $21^{\circ}$ [22], and no other peaks of $\mathrm{V}_{2} \mathrm{O}_{5}$ revealing that the $\mathrm{V}_{2} \mathrm{O}_{5}$ in $\mathrm{HCl}$ medium does not induce its properties and act only as a catalyst just to enhance the polymerization reaction during the formation of PDPA polymer. On the other hand, XRD pattern of $\mathrm{V}_{2} \mathrm{O}_{5}$ and PDPA $/ \mathrm{V}_{2} \mathrm{O}_{5}$ composite, as shown in our earlier work, exhibited the characteristic peaks of $\mathrm{V}_{2} \mathrm{O}_{5}$ with low intensity and without any characteristic shift was observed [27]. The decreased intensity with no shift in peaks revealed that the structure of $\mathrm{V}_{2} \mathrm{O}_{5}$ has not been destroyed and the formation of PDPA has occurred on the surface of $\mathrm{V}_{2} \mathrm{O}_{5}$.

\subsection{Thermal stability}

The thermal stability of PDPA $/ \mathrm{V}_{2} \mathrm{O}_{5}$ and PDPA respectively, are shown in Fig. 5. The thermogram revealed that initially PDPA $/ \mathrm{N}_{2} \mathrm{O}_{5}$ losses $18 \mathrm{wt} \%$ in the range of $123-220^{\circ} \mathrm{C}$, while PDPA shows $8 \mathrm{wt} \%$ loss at $180-260^{\circ} \mathrm{C}$. More weight loss in case of PDPA $/ \mathrm{N}_{2} \mathrm{O}_{5}$ in this range may be due to the 

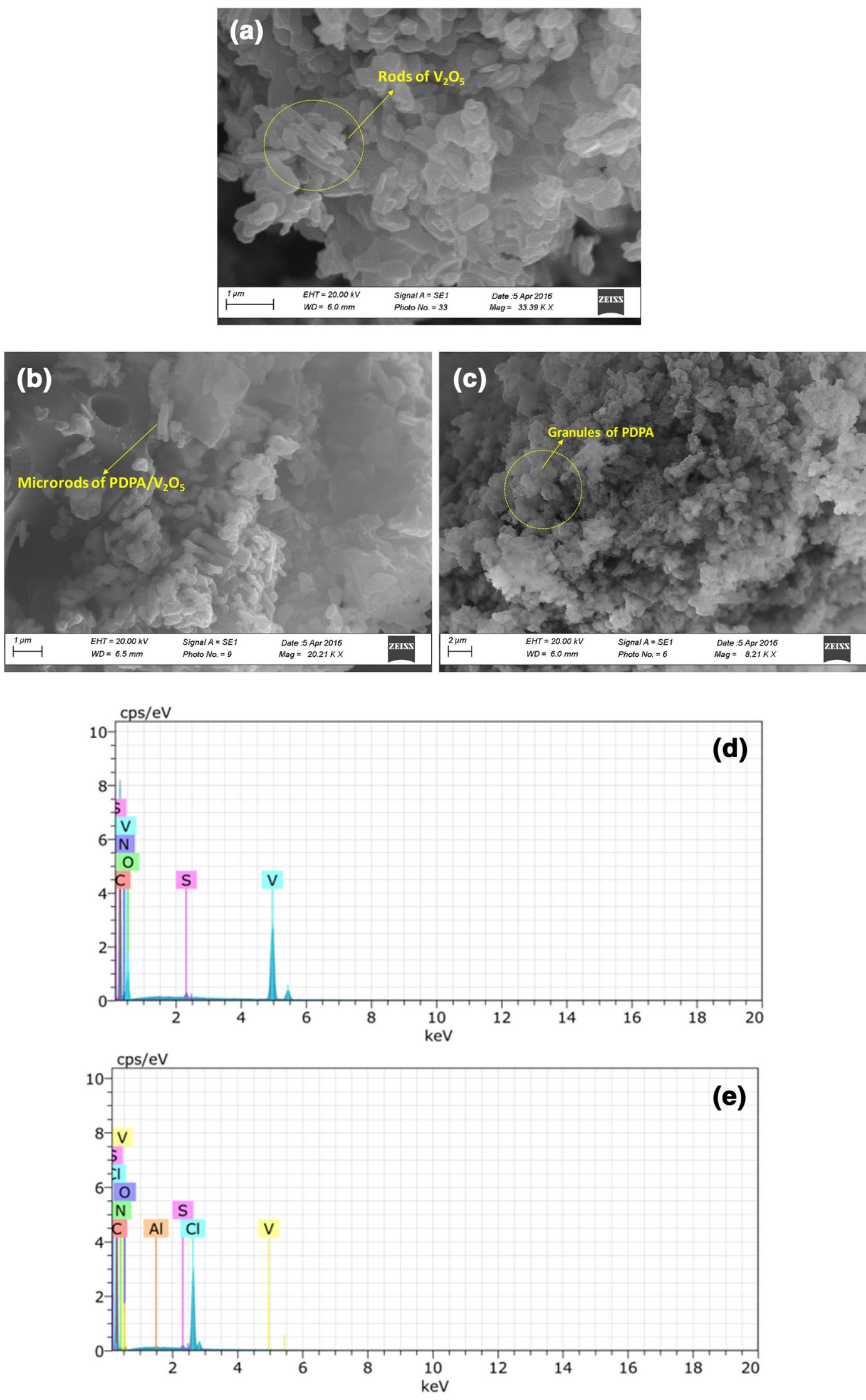

Fig. 3 SEM micrograph of $\mathbf{a} \mathrm{V}_{2} \mathrm{O}_{5}$ b PDPA $/ \mathrm{V}_{2} \mathrm{O}_{5}$ c PDPA and EDS spectra of $\mathbf{d}$ PDPA $/ \mathrm{V}_{2} \mathrm{O}_{5}$ and e PDPA 
Fig. 4 XRD patterns of $\mathbf{a} \mathrm{V}_{2} \mathrm{O}_{5}$ b PDPA $/ \mathrm{V}_{2} \mathrm{O}_{5}$ composite and c PDPA

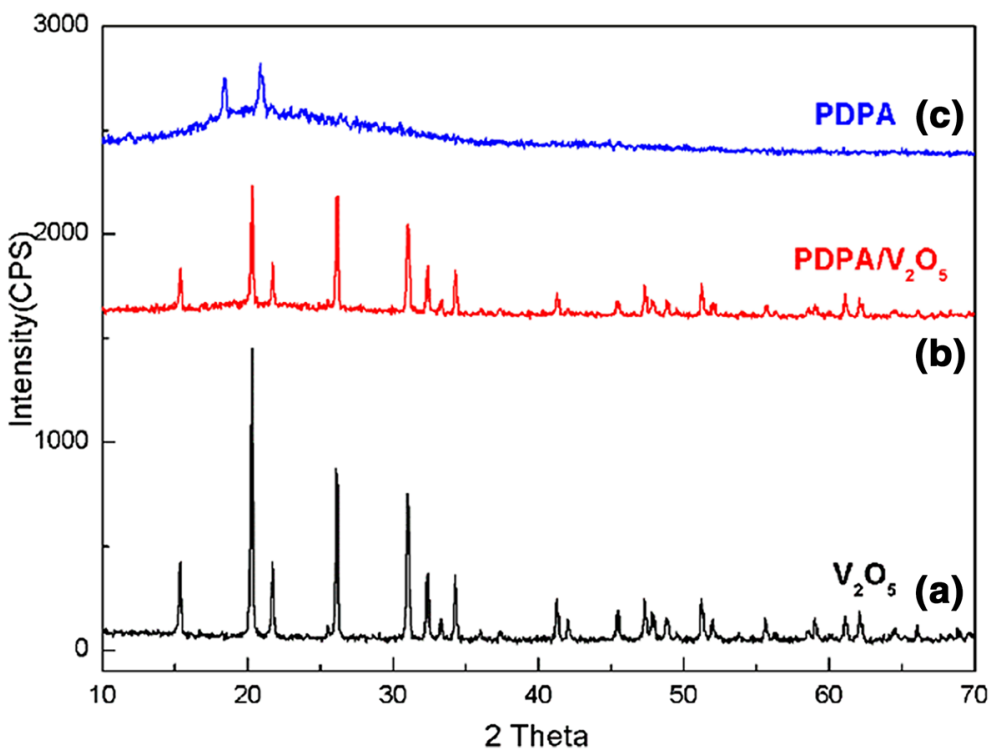

Fig. 5 TGA of PDPA/ $\mathrm{V}_{2} \mathrm{O}_{5}$ composite and PDPA

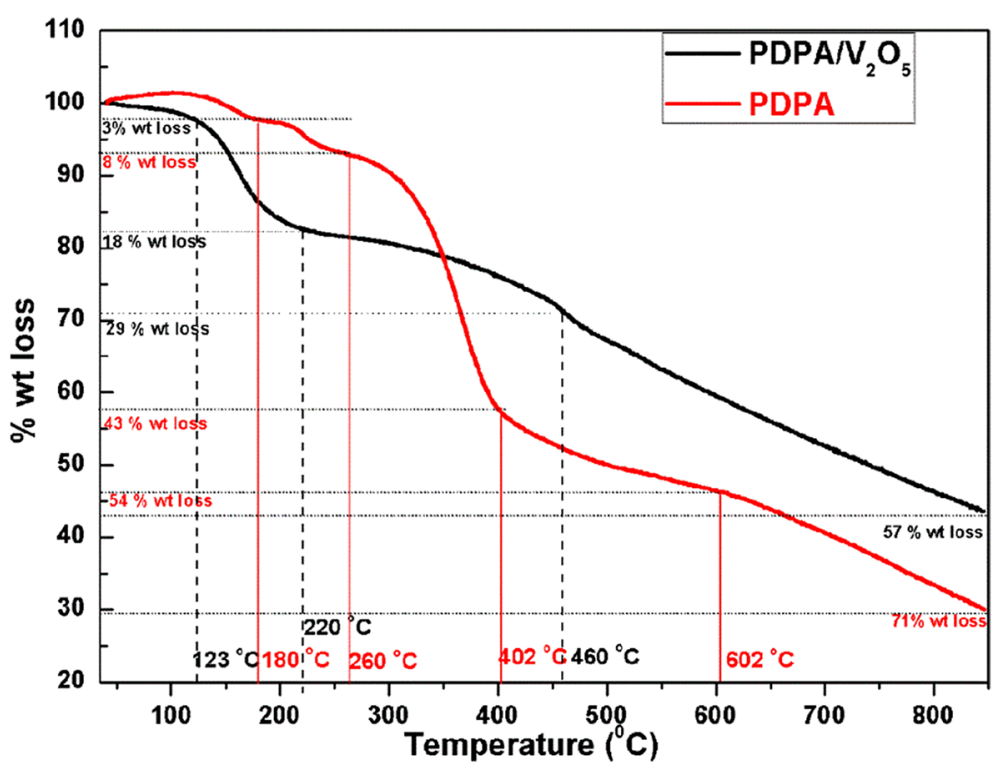

combined loss of weakly bound interlamellar water and tightly bound intralamellar water [12, 28, 29]. Beyond $260{ }^{\circ} \mathrm{C}$ the PDPA exhibit a steep decomposition pattern up to $402{ }^{\circ} \mathrm{C}$, while PDPA $/ \mathrm{V}_{2} \mathrm{O}_{5}$ shows a second sluggish decomposition in the temperature range of $220-460^{\circ} \mathrm{C}$. This can be attributed to the loss of low molecular weight oligomers [30]. Beyond this, both the PDPA and PDPA $/ \mathrm{N}_{2} \mathrm{O}_{5}$ composite undergo a continuous degradation up to $850^{\circ} \mathrm{C}$, owing to the degradation of main polymer chain [16]. It is further noticed here that after $402^{\circ} \mathrm{C}$ the PDPA follow a sluggish decomposition pattern while PDPA $/ \mathrm{N}_{2} \mathrm{O}_{5}$ shows a sharp decomposition with less weight loss. It is important to mention here that both the PDPA $/ \mathrm{N}_{2} \mathrm{O}_{5}$ and PDPA behave differently at low and high temperature. At low temperature (up to $260^{\circ} \mathrm{C}$ ) PDPA is more stable than PDPA $/ \mathrm{V}_{2} \mathrm{O}_{5}$ while at higher temperature (above $360^{\circ} \mathrm{C}$ ) PDPA $/ \mathrm{V}_{2} \mathrm{O}_{5}$ is more stable. The reason for low stability of PDPA $/ \mathrm{N}_{2} \mathrm{O}_{5}$ at low temperature is due to the removal of trapped water. The result also suggest that the wrapping of PDPA over the surface of $\mathrm{V}_{2} \mathrm{O}_{5}$ rods forms a sandwich like structure which leads to higher thermal stability at higher temperature.

\subsection{Electrical conductivity}

The temperature dependent DC conductivity was measured in the temperature range of $364-463 \mathrm{~K}$ using constant voltage of $1.5 \mathrm{~V}$, which is shown in Fig. 6 . The dc conductivity of both PDPA and PDPA $/ \mathrm{V}_{2} \mathrm{O}_{5}$ composite increased with the increasing temperature, this can be attributed to the increase in thermal vibration activity 
that led to the formation of polaron and bipolaron along the conjugated chains of the polymers. Thus, the mobility of charge carriers (polarons and bipolarons) increases with the increase in temperature that led to the increase in the electrical conductivity [31].

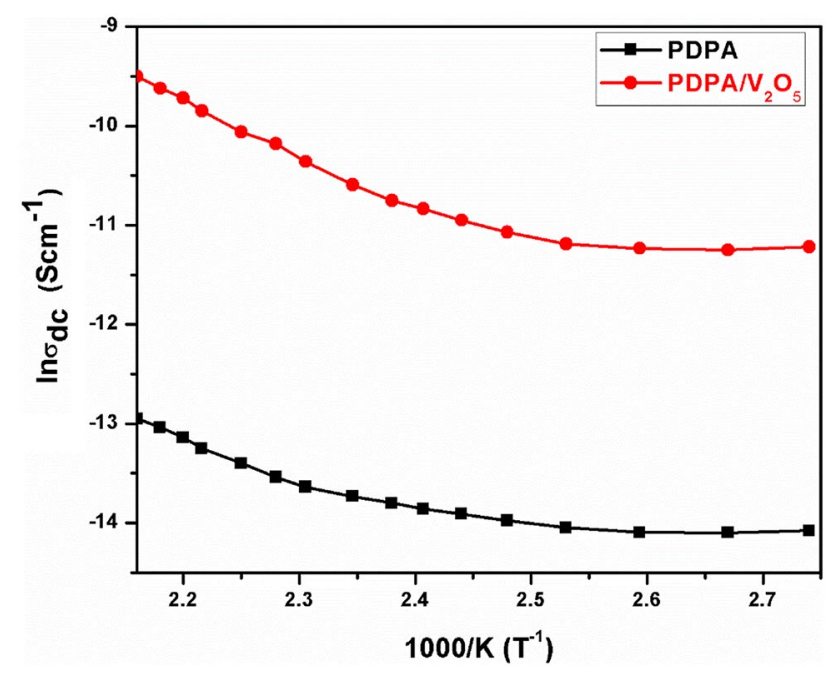

Fig. 6 Temperature dependent DC conductivity of PDPA and PDPA/ $\mathrm{V}_{2} \mathrm{O}_{5}$
It is worth to note here, that the temperature dependent dc conductivity of the PDPA/ $\mathrm{V}_{2} \mathrm{O}_{5}$ composite is 2 fold higher than that of PDPA (Fig. 6). This can be due to the stability associated with the wrapping of $\mathrm{V}_{2} \mathrm{O}_{5}$ with PDPA matrix in aqueous medium, which results in the formation of more polaron and bipolaron that led to the enhancement of conductivity. Moreover, In case of composite (PDPA $/ \mathrm{V}_{2} \mathrm{O}_{5}$ ), the formation of $\mathrm{VO}^{2+}$ occurs with the increase in temperature, which further helps in the transfer of electrons within the composite that also causes an increase in conductivity [32,33]. A proposed conduction mechanism in PDPA $/ \mathrm{N}_{2} \mathrm{O}_{5}$ composite is depicted in Fig. $7 \mathrm{a}$, which showed that with the increase in temperature electron mobility (polarons and bipolarons) increases within the composite as a result transfer of electron is observed i.e. from HOMO to LUMO (shown in Fig. 7b), which lead to the increase in conductivity.

\subsection{Dielectric properties}

The dielectric behaviour of PDPA and PDPA $/ \mathrm{V}_{2} \mathrm{O}_{5}$ composite were analysed using an impedance analyser in the frequency range of $100 \mathrm{~Hz}-1 \mathrm{MHz}$ and are shown in Fig 8 . The dielectric constant and dielectric loss were found to

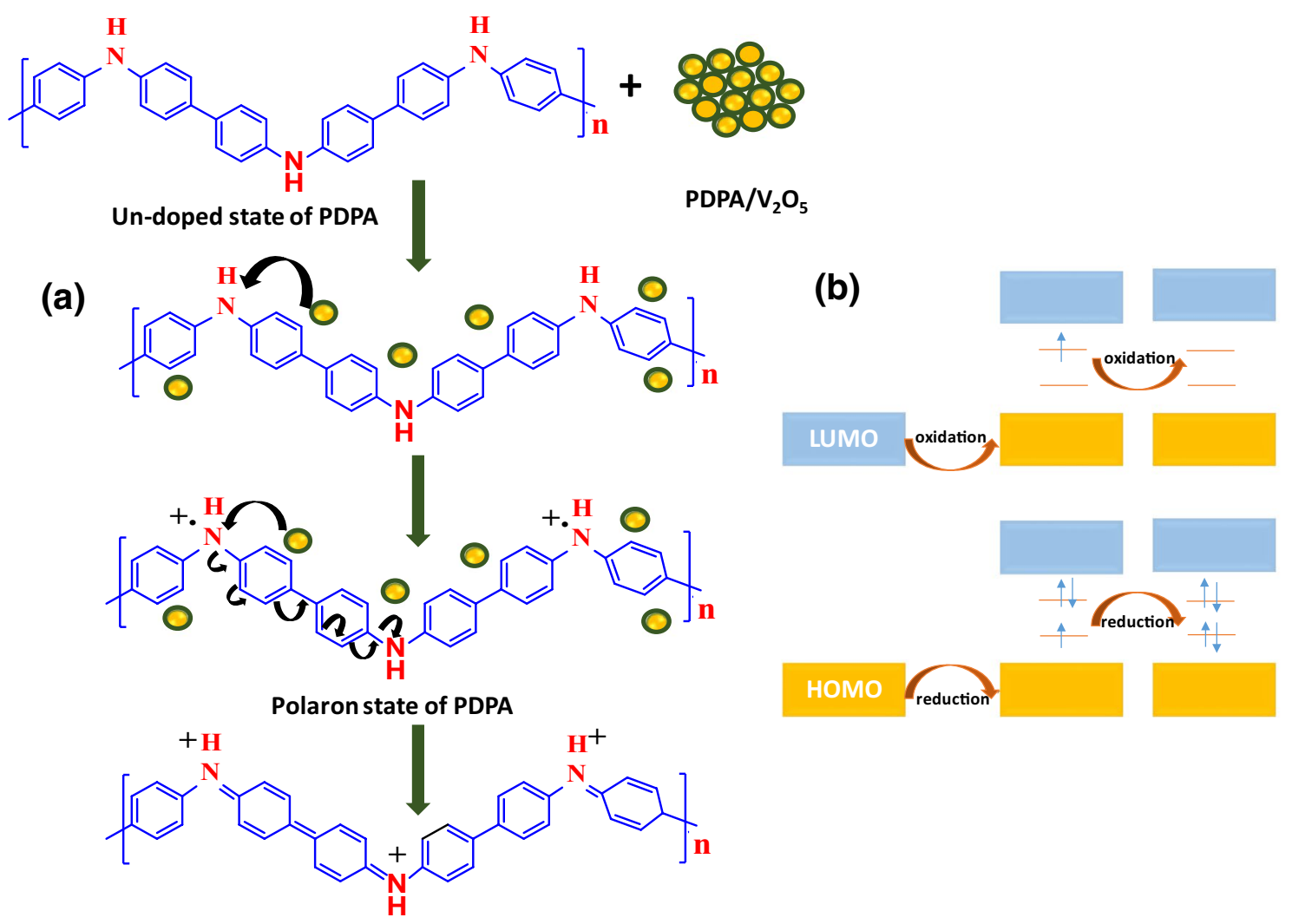

Bi-polaron state of PDPA

Fig. 7 a Conduction mechanism in PDPA $/ \mathrm{N}_{2} \mathrm{O}_{5}$ composite and $\mathbf{b}$ transfer of electrons 
decrease with the increase in frequency due to dielectric dispersion as a result of the polarization of molecules during the alternation of the electric field at higher frequency, which is in well agreement with the Maxwell-Wagner interfacial polarization and Koop's model [34, 35]. It was observed that the PDPA $/ \mathrm{V}_{2} \mathrm{O}_{5}$ composite formed in aqueous medium showed superior dielectric properties as compared to that of PDPA, which is formed in acidic medium. At low frequency $(100 \mathrm{~Hz})$, the dielectric constant values of PDPA and PDPA $/ \mathrm{N}_{2} \mathrm{O}_{5}$ composite was 214.39 and 245.32 while at high frequency $(1 \mathrm{MHz})$ the dielectric constant of the same was found to be 99.17 and 166.47, respectively. On the other hand, the dielectric loss ( $\tan \delta$ ) of PDPA and PDPA $/ \mathrm{V}_{2} \mathrm{O}_{5}$ composite was found to be $0.86 / 0.21$ at low frequency $(1 \mathrm{kHz})$ and $0.17 / 0.09$ at high frequency $(1 \mathrm{MHz})$, respectively. Further, the PDPA $/ \mathrm{V}_{2} \mathrm{O}_{5}$ composite exhibited much lower dielectric loss than that of PDPA, which suggest that PDPA $/ \mathrm{N}_{2} \mathrm{O}_{5}$ composite synthesized in aqueous medium exhibits better dielectric properties than that of PDPA and may find a potential application in the field of capacitors, and battery.

\subsection{Electrochemical properties}

To study the influence of medium on electrochemical activities of PDPA $/ \mathrm{V}_{2} \mathrm{O}_{5}$ composite and PDPA polymer, the cyclic voltammetry were carried out in $0.5 \mathrm{M} \mathrm{H}_{2} \mathrm{SO}_{4}$ aqueous electrolyte at the scan rate of $2 \mathrm{mV} / \mathrm{s}$ in the potential range +1.2 to $-1.2 \mathrm{~V}$ versus $\mathrm{Ag} / \mathrm{Ag}^{+}$. The cyclic voltammograms (CV) of PDPA $/ \mathrm{V}_{2} \mathrm{O}_{5}$ composite and PDPA polymer have shown in Fig. 9a. It is observed that the oxidation and reduction potentials were found to be different for PDPA/ $\mathrm{V}_{2} \mathrm{O}_{5}$ and PDPA. PDPA $/ \mathrm{V}_{2} \mathrm{O}_{5}$ exhibit single anodic (anodic) and cathodic (reduction) peaks at $1.02 \mathrm{~V}$ and $0.50 \mathrm{~V}$,
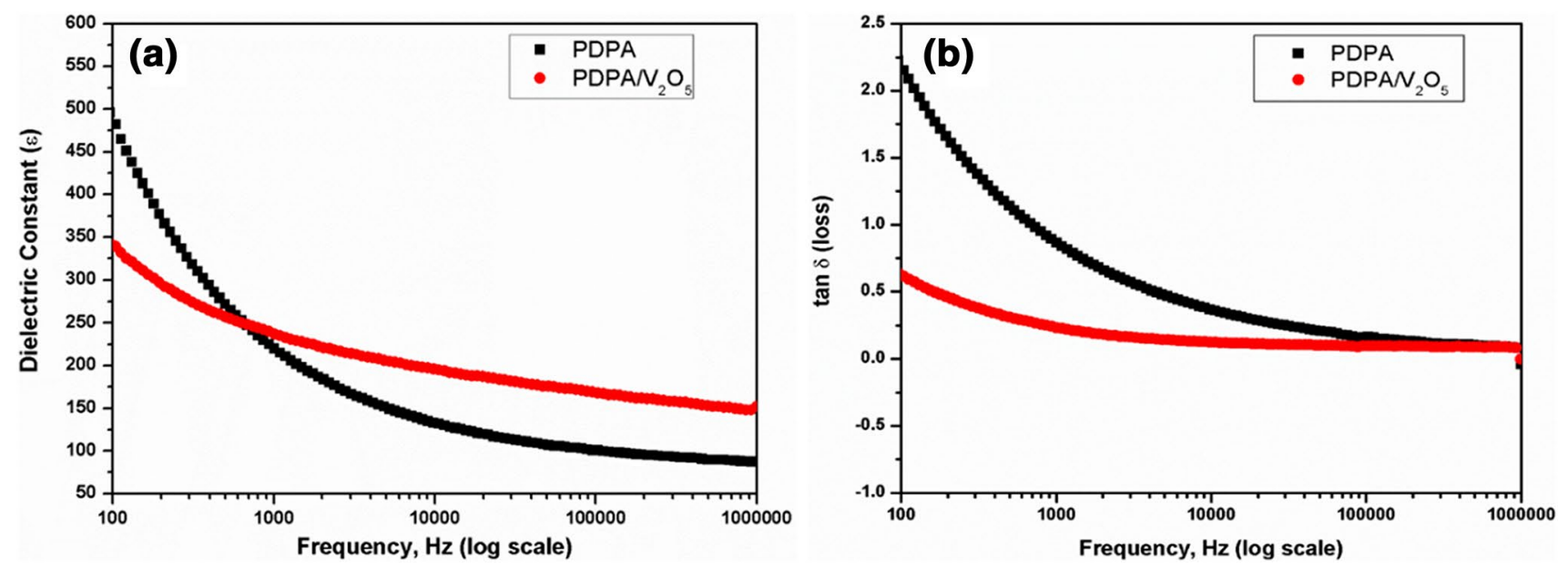

Fig. 8 a Dielectric constant and $\mathbf{b}$ dielectric loss of PDPA and PDPA $/ \mathrm{V}_{2} \mathrm{O}_{5}$ composite
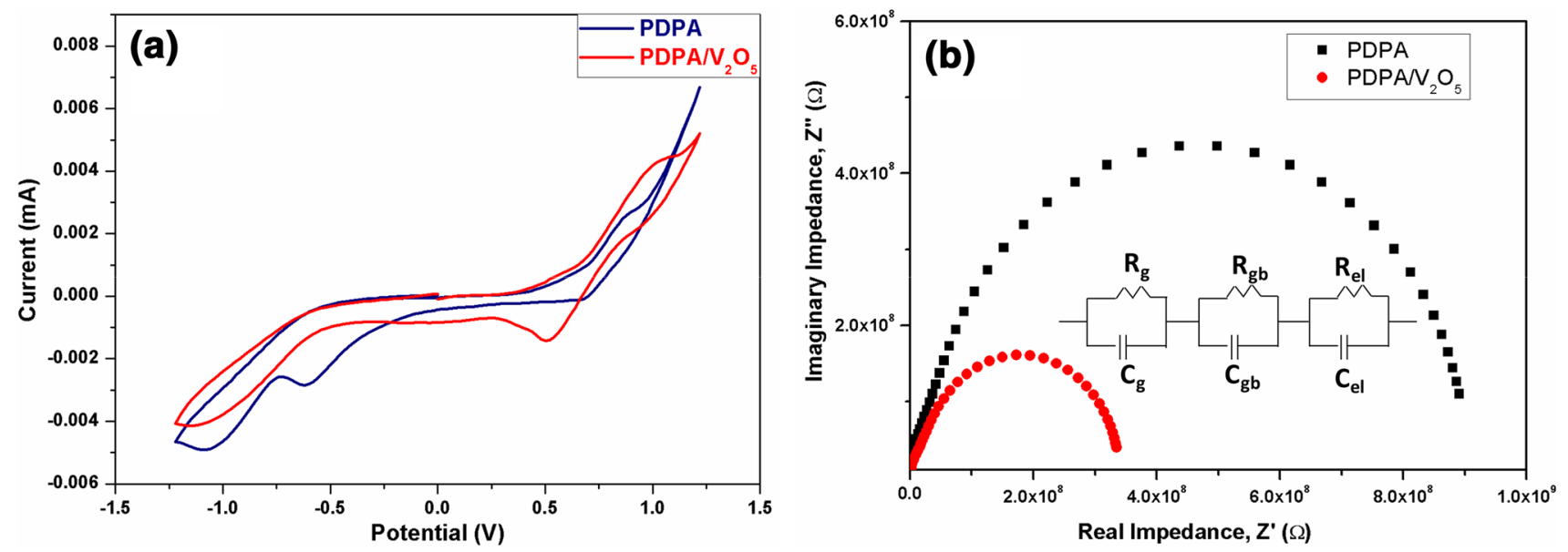

Fig. 9 a Cyclic voltammetry b Nyquist plot of PDPA and PDPA/ $\mathrm{V}_{2} \mathrm{O}_{5}$ composite 
respectively. While the PDPA shows, single anodic (oxidation) peaks at $0.87 \mathrm{~V}$ and double cathodic (reduction) peaks at $0.68 \mathrm{~V}$ and $-0.62 \mathrm{~V}$, respectively. On one hand, PDPA $/ \mathrm{V}_{2} \mathrm{O}_{5}$ exhibits broader peak within the range of positive potential, on the other hand, PDPA shows the broader peak in negative potential range. Another distinguished feature is that the oxidative current density peak of PDPA/ $\mathrm{V}_{2} \mathrm{O}_{5}$ composite is higher than that of PDPA. This can be attributed to the charge transfer at the electrode-electrolyte interface in PDPA $/ \mathrm{V}_{2} \mathrm{O}_{5}$ composite is faster than that of PDPA. The CV curve of the PDPA/ $\mathrm{V}_{2} \mathrm{O}_{5}$ shows slightly larger area than that of PDPA indicating that PDPA $/ \mathrm{V}_{2} \mathrm{O}_{5}$ can exhibit a better capacitive behaviour [36].

The electrochemical properties (capacitance and resistance) of PDPA and PDPA $/ \mathrm{V}_{2} \mathrm{O}_{5}$ composites were further examined with the help of EIS measurement. The imaginary impedance ( $\left.Z^{\prime \prime}\right)$ versus real impedance $\left(Z^{\prime}\right)$ is a Nyquist plot (Fig. 9b) of the same was recorded. The curves exhibit a semicircle at high and low frequency region, which corresponds to the charge transfer reaction at electrode/ electrolyte interface $[37,38]$. The PDPA $/ \mathrm{V}_{2} \mathrm{O}_{5}$ composite displayed a semicircle with smaller diameter than that of PDPA. This indicates that the PDPA $/ \mathrm{V}_{2} \mathrm{O}_{5}$ composite exhibits low impedance on electrode-electrolyte interface [39].

An inset shows a simple equivalent circuit model used to simulate the impedance spectra of these composites. In this circuit, $R_{g}, R_{g b}$ and $R_{e l}$ are the grain, grain boundaries and electrode resistances whereas, $C_{g}, C_{g b}$ and $C_{e l}$ represent the grain, grain boundaries and electrode capacitances while $R_{e l}$ and $C_{e l}$ represent the electrode resistance and capacitance, respectively. The fitted values for the resistance and capacitance of PDPA $/ \mathrm{V}_{2} \mathrm{O}_{5}$ composite and PDPA are given in Table 1. The high resistance of grain

Table 1 Resistance and capacitance values (fitted to the parameters in the Nyquist plot) of PDPA $/ \mathrm{N}_{2} \mathrm{O}_{5}$ and PDPA

\begin{tabular}{lll}
\hline Resistance and capacitance & PDPA/ $/ \mathrm{V}_{2} \mathrm{O}_{5}$ & PDPA \\
\hline $\mathrm{R}_{\mathrm{g}}$ & $1.2 \mathrm{~K} \Omega$ & $1.9 \mathrm{~K} \Omega$ \\
$\mathrm{R}_{\mathrm{gb}}$ & $20.1 \mathrm{M} \Omega$ & $63.4 \mathrm{M} \Omega$ \\
$\mathrm{R}_{\mathrm{el}}$ & $328 \mathrm{M} \Omega$ & $880 \mathrm{M} \Omega$ \\
$\mathrm{C}_{\mathrm{g}}$ & $13.8 \mathrm{nF}$ & $14.8 \mathrm{nF}$ \\
$\mathrm{C}_{\mathrm{gb}}$ & $0.42 \mathrm{pF}$ & $1.12 \mathrm{pF}$ \\
$\mathrm{C}_{\mathrm{el}}$ & $0.15 \mathrm{pF}$ & $0.68 \mathrm{pF}$ \\
\hline
\end{tabular}

boundaries $\left(R_{g b}\right)$ in PDPA may be attributed to the presence of defects in the grain boundaries, which trapped the conducting charges. At high frequency, the value of grain capacitance $\left(C_{g}\right)$ and resistance $\left(R_{g}\right)$ was $13.8 \mathrm{nF}$ and $1.2 \mathrm{k} \Omega$ for PDPA $/ \mathrm{V}_{2} \mathrm{O}_{5}$ composite and $14.8 \mathrm{nF}$ and $1.9 \mathrm{k} \Omega$ for PDPA. Moreover, the low $\mathrm{R}_{\mathrm{el}}$ value $(328 \mathrm{M} \Omega$ ) for PDPA/ $\mathrm{V}_{2} \mathrm{O}_{5}$ composite as compared to PDPA polymer ( $880 \mathrm{M} \Omega$ ) further suggests higher ionic conductivity for PDPA/ $/ \mathrm{V}_{2} \mathrm{O}_{5}$ composite than PDPA polymer. This may be attributed to the ease of release of trapped charges in aqueous medium than that of acid medium, which is well in agreement with conductivity measurement [40].

These studies revealed that the reaction medium plays an important role in the synthesis, structure, and morphology of these materials. The reaction medium also affects the thermal, electrical and electrochemical properties of PDPA and PDPA $/ \mathrm{V}_{2} \mathrm{O}_{5}$, which are summarized in Table 2 .

\section{Conclusion}

In the present study, we have discussed the influence of reaction medium (aqueous and acidic) on the formation of PDPA and PDPA $/ \mathrm{V}_{2} \mathrm{O}_{5}$ composite for the first time. The synthesis were facile and one pot. The structural, morphological, electrical and thermal properties are tuned just by the changing the reaction medium i.e. acidic to aqueous medium. XRD and EDX analysis revealed that in aqueous medium PDPA $/ \mathrm{V}_{2} \mathrm{O}_{5}$ composite has formed, while in case of acidic medium only the PDPA polymer is formed, as in acidic medium $\mathrm{V}_{2} \mathrm{O}_{5}$ acts only as a catalyst that finally leaches out. Additionally, SEM analysis revealed that the PDPA showed granules while PDPA $/ \mathrm{V}_{2} \mathrm{O}_{5}$ exhibits rod like morphology. TGA studies revealed that PDPA $/ \mathrm{V}_{2} \mathrm{O}_{5} \mathrm{com}$ posite displayed excellent thermal properties (i.e. char residue of $43 \%$ at $850^{\circ} \mathrm{C}$ ) than PDPA (char residue of $29 \%$ at $850^{\circ} \mathrm{C}$ ). The electrical conductivity at $463 \mathrm{~K}$ for PDPA/ $\mathrm{V}_{2} \mathrm{O}_{5}$ composite was found to be $7.44 \times 10^{-5} \mathrm{~S} \mathrm{~cm}^{-1}$, which is higher than that of PDPA $\left(2.36 \times 10^{-6} \mathrm{~S} \mathrm{~cm}^{-1}\right)$. Moreover, PDPA $/ \mathrm{V}_{2} \mathrm{O}_{5}$ composite exhibited superior dielectric properties (i.e. dielectric constant of 257.32 at $1 \mathrm{kHz}$ ), which is much higher than that of PDPA (218.39 at $1 \mathrm{kHz}$ ). Thus, these studies revealed that the aqueous medium is suitable for the synthesis of PDPA $/ \mathrm{V}_{2} \mathrm{O}_{5}$ composite to avail better properties. Thus, it can be concluded that PDPA/

Table 2 Various properties of PDPA/ $\mathrm{V}_{2} \mathrm{O}_{5}$ composite and PDPA polymer

\begin{tabular}{lllcccc}
\hline Composites & Yield (gm) & Morphology & Conductivity S cm ${ }^{-1}$ & $\begin{array}{l}\text { Char residue } \\
(\%)\end{array}$ & $\begin{array}{l}\text { Dielectric con- } \\
\text { stant }(\varepsilon)\end{array}$ & Dielectric loss \\
\hline PDPA $/ \mathrm{V}_{2} \mathrm{O}_{5}$ & 0.721 & Rods like & $7.44 \times 10^{-5}$ & 43 & 245.32 & 0.21 \\
PDPA & 0.569 & Granular structures & $3.0 \times 10^{-6}$ & 29 & 214.39 & 0.86 \\
\hline
\end{tabular}


$\mathrm{V}_{2} \mathrm{O}_{5}$ composite has a potential scope in the field of energy storage devices e.g. capacitor and batteries.

Acknowledgements One of the author, Halima Khatoon, gratefully acknowledge MANF-UGC (F1-17.1/2014-15) for financial assistance. We further extend our sincere thanks to Dr. Javed Alam, Department of Physics, Jamia Millia Islamia, for temperature dependent dc conductivity measurement.

\section{Compliance with ethical standards}

Conflict of interest The authors declare that they have no conflict of interests.

\section{References}

1. Jaidev JR, Mishra AK, Ramaprabhu S (2011) Polyaniline- $\mathrm{MnO}_{2}$ nanotube hybrid nanocomposite as supercapacitor electrode material in acidic electrolyte. J Mater Chem 21:17601. https:// doi.org/10.1039/c1jm13191e

2. Mondal S, Rana U, Malik S (2015) Graphene quantum dot-doped polyaniline nanofiber as high performance supercapacitor electrode materials. Chem Commun 51:12365-12368. https://doi. org/10.1039/C5CC03981A

3. Jiang J, Li Y, Liu J, Huang X, Yuan C, Wen X (2012) Recent advances in metal oxide-based electrode architecture design for electrochemical energy storage. Adv Mater 24:5166-5180

4. Iqbal S, Ahmad S (2018) Recent development in hybrid conducting polymers: synthesis, applications and future prospects. J Ind Eng Chem 60:53-84. https://doi.org/10.1016/j. jiec.2017.09.038

5. Navale YH, Ingole SM, Navale ST, Stadler FJ, Mane RS, Naushad M, Patil VB (2017) Electro-synthesized fibrous polyaniline electrode as an active electrochemical supercapacitor material. J Colloid Interface Sci 487:458. https://doi.org/10.1016/j.jcis.2016.09.038

6. Williams EL, Jabbour GE, Wang Q, Shaheen SE, Ginley DS, Schiff EA (2005) Conducting polymer and hydrogenated amorphous silicon hybrid solar cells. Appl Phys Lett 87(22):223504

7. Riaz U, Ahmad SA, Ashraf SM, Ahmad S (2009) Effect of dopant on the corrosion protective performance of environmentally benign nanostructured conducting composite coatings. Prog Org Coat 65:405-409. https://doi.org/10.1016/j.porgc oat.2009.01.005

8. Zate MK, Shaikh SMF, Jadhav VV, Tehare KK, Kolekar SS, Mane RS, Naushad M, Pawar BN, Hui KN (2015) Synthesis and electrochemical supercapacitive performance of nickel-manganese ferrite composite films. J Anal Appl Pyrol 116:177-182. https:// doi.org/10.1016/j.jaap.2015.09.012

9. Navale ST, Mali VV, Pawar SA, Mane RS, Naushad M, Stadler FJ, Patil VB (2015) Electrochemical supercapacitor development based on electrodeposited nickel oxide film. RSC Adv 5(64):51961-51965. https://doi.org/10.1039/c0xx00000x

10. Guo CX, Sun K, Ouyang J, Lu X (2015) Layered $V_{2} \mathrm{O}_{5} /$ PEDOT nanowires and ultrathin nanobelts fabricated with a silk reelinglike process. Chem Mater 27:5813-5819. https://doi. org/10.1021/acs.chemmater.5b02512

11. Pang S, Li G, Zhang Z (2005) Synthesis of polyaniline-vanadium oxide nanocomposite nanosheets. Macromol Rapid Commun 26:1262-1265. https://doi.org/10.1002/marc.200500235

12. Murugan AV, Kale BB, Kwon CW (2001) Synthesis and characterization of a new organo-inorganic poly(3,4-ethylene dioxythiophene) PEDOT $/ \mathrm{V}_{2} \mathrm{O}_{5}$ nanocomposite by intercalation. J Mater Chem 11:2470-2475. https://doi.org/10.1039/ b100714i

13. Boyano I, Bengoechea $M$, de Meatza I (2007) Improvement in the Ppy $/ \mathrm{V}_{2} \mathrm{O}_{5}$ hybrid as a cathode material for $\mathrm{Li}$ ion batteries using PSA as an organic additive. J Power Sources 166:471-477. https ://doi.org/10.1016/j.jpowsour.2006.12.106

14. Permpool T, Sirivat A, Aussawasathien D (2014) Synthesis of polydiphenylamine with tunable size and shape via emulsion polymerization. Polym Int 63:2076-2083. https://doi. org/10.1002/pi.4745

15. Athawale A, Deore B, Chabukswar V (1999) Studies on poly(diphenylamine) synthesized electrochemically in nonaqueous media. Mater Chem Phys 58:94-100. https://doi. org/10.1016/S0254-0584(98)00258-2

16. Showkat A, Cao X, Kim DW, Islam R (2015) Characterization of poly(diphenylamine)-gold nanocomposites obtained by self-assembly. Mater Sci Eng. https://doi.org/10.1088/1757899X/77/1/012007

17. Yang C, Chen S, Tsai T, Unnikrishnan B (2012) Poly(diphenylamine) with multi-walled carbon nanotube composite film modified electrode for the determination of phenol. Int J Electrochem Sci 7:12796-12807

18. Liu Z, Liu Y, Poyraza S, Zhang X (2011) Green-nano approach to nanostructured polypyrrole. Chem Commun 47:4421-4423. https://doi.org/10.1039/c1cc10208g

19. Lia T, Zhou Y, Liang B, Jin D, Liu N, Qin Z, Zhu M (2017) Onepot synthesis and electrochemical properties of polyaniline nanofibers through simply tuning acid-base environment of reaction medium. Electrochimica Acta 249:33-42. https://doi. org/10.1016/j.electacta.2017.07.177

20. Krukiewicz K, Katunin A (2016) The effect of reaction medium on the conductivity and morphology of polyaniline doped with camphorsulfonic acid. Synth Metals 214:45-49. https://doi. org/10.1016/j.synthmet.2016.01.017

21. Khatoon H, Ahmad S (2019) Vanadium pentoxide enwrapped polydiphenylamine/polyurethane nanocomposite: high performance anticorrosive coating. ACS Appl Mater Interfaces 11:2374-2385. https://doi.org/10.1021/acsami.8b17861

22. Lu X, Chao D, Zheng J (2006) Preparation and characterization of polydiphenylamine/multi-walled carbon nanotube composites. Polym Int 55:945-950. https://doi.org/10.1002/pi.2046

23. Zhao Y, Chen M, Liu X (2005) Electrochemical synthesis of polydiphenylamine nanofibrils through AAO template. Mater Chem Phys 91:518-523. https://doi.org/10.1016/j.matchemphy s.2004.12.019

24. Khairy M (2014) Synthesis, characterization, magnetic and electrical properties of polyaniline/ $\mathrm{NiFe}_{2} \mathrm{O}_{4}$ nanocomposite. Synth Met 189:34-41. https://doi.org/10.1016/j.synthmet.2013.12.022

25. Avansi W Jr, Ribeiro C, Leite ER, Mastelaro CR (2009) Vanadium pentoxide nanostructures: an effective control of morphology and crystal structure in hydrothermal conditions. Cryst Growth Des 9:3626-3631

26. Anicic N, Vukomanovic M, Suvorov D (2017) Design of a multifunctional vanadium pentoxide/polymer biocomposite for implant-coating applications. RSC Adv 7:38647-38658. https:// doi.org/10.1039/c7ra06471c

27. Mai L, Dong F, Xu X et al (2013) Cucumber-like $\mathrm{V}_{2} \mathrm{O}_{5}$ /poly(3,4ethylenedioxythiophene) $\& \mathrm{MnO}_{2}$ nanowires with enhanced electrochemical cyclability. Nano Lett 13:740-745

28. Umeshbabu E, Rao GR (2016) Vanadium pentoxide nanochains for high-performance electrochemical supercapacitors. J Colloid Interface Sci 472:210-219. https://doi.org/10.1016/j. jcis.2016.03.050

29. Li L, Yan Z (2005) Synthesis and characterization of self-assembled $\mathrm{V}_{2} \mathrm{O}_{5}$ mesostructures intercalated by polyaniline. $\mathrm{J}$ Nat 
Gas Chem 14:35-39. https://doi.org/10.1016/j.composites b.2013.02.041

30. Ozkan SZ, Karpacheva GP, Orlov V, Dzyubina M (2007) Thermal stability of polydiphenylamine synthesized through oxidative polymerization of diphenylamine. Polym Sci Ser B 49:36-41. https://doi.org/10.1134/S1560090407010095

31. Baig U, Wani WA, Hun LT (2015) Facile synthesis of an electrically conductive polycarbazole-zirconium (iv) phosphate cation exchange nanocomposite and its room temperature ammonia sensing performance. New J Chem 39:6882-6891. https://doi. org/10.1039/C5NJ01029B

32. Wu C, Degroot DC, Marcy HO (1996) Redox intercalative polymerization of aniline in $\mathrm{V}_{2} \mathrm{O}_{5}$ xerogel. The Postintercalative intralamellar polymer growth in polyaniline/metal oxide nanocomposites is facilitated by molecular oxygen. Chem Mater 8:1992-2004

33. Chun-Guey W, Jiunn-Yih H, Shui-Sheng $H$ (2001) Synthesis and characterization of processible conducting polyaniline $/ \mathrm{V}_{2} \mathrm{O}_{5}$ nanocomposites. J Mater Chem 11:2061-2066. https://doi. org/10.1039/b009419f

34. Islam S, Lakshmi GBVS, Siddiqui AM (2013) Synthesis, electrical conductivity, and dielectric behavior of polyaniline $/ \mathrm{V}_{2} \mathrm{O}_{5} \mathrm{com}$ posites. Int J Polym Sci 2013:1-7

35. Chwang C, Liu C, Huang S (2004) Synthesis and characterization of high dielectric constant polyaniline/polyurethane blends. Synth Metals 142:275-281. https://doi.org/10.1016/j.synth met.2003.09.012

36. Rajesh B, Thampi KR, Bonard JM (2004) Template synthesis of conducting polymeric nanocones of poly(3-methylthiophene).
J Phys Chem B 108:10640-10644. https://doi.org/10.1021/jp030 623

37. Bhande SS, Ambade RB, Shinde DV, Ambade SB, Patil SA, Naushad M, Mane RS, Alothman ZA, Lee SH, Han SH (2015) Improved photoelectrochemical cell performance of tin oxide with functionalized multiwalled carbon nanotubes-cadmium selenide sensitizer. ACS Appl Mater Interfaces 7(45):25094-25104. https ://doi.org/10.1021/acsami.5b05385

38. Zate MK, Jadhav VV, Gore SK, Shendkar JH, Ekar SU, Al-Osta A, Naushad M, Mane RS (2016) Structural, morphological and electrochemical supercapacitive properties of sprayed manganese ferrite thin film electrode. J Anal Appl Pyrol 122:224-229. https ://doi.org/10.1016/j.jaap.2016.09.020

39. Jafri RI, Mishra AK, Ramaprabhu S (2011) Polyaniline- $\mathrm{MnO}_{2}$ nanotube hybrid nanocomposite as supercapacitor electrode material in acidic electrolyte. J Mater Chem 21(44):17601-17605. https://doi.org/10.1039/C1JM13191E

40. Shah J, Kotnala RK (2017) Rapid green synthesis of ZnO nanoparticles using a hydroelectric cell without an electrolyte. J Phys Chem Solids 108:15-20. https://doi.org/10.1016/j. jpcs.2017.04.007

Publisher's Note Springer Nature remains neutral with regard to jurisdictional claims in published maps and institutional affiliations. 